IP Periodica Polytechnica

Mechanical Engineering

60(4), pp. 220-227, 2016

DOI: 10.3311/PPme. 8816

Creative Commons Attribution (i)

RESEARCH ARTICLE

\section{Development of a Multi-Point Injection System Operating on Superheated Alcohol Fuels and Evaluation of Toxicity of Their Combustion Products}

\author{
Aleksey Egorov ${ }^{1}$, Konstantin Kozlov ${ }^{1 *}$, Vladimir Belogusev ${ }^{1}$
}

Received 18 November 2015; accepted after revision 23 June 2016

\begin{abstract}
This article is devoted to the development of a fuel injection system for internal combustion engines (ICEs or engines) with positive ignition, which operates on superheated fuels. Such systems allow engines securely starting and working on absolute (96\%) alcohol, even in low temperature environments. This article describes the operation principle of a multi-point superheated fuels injection system; and the comparison analysis of thermal efficiency and heat balances of both the baseline gasoline engine and the engine with a developed superheated alcohol-based fuel injection system is provided. In experimental studies, the contents of $\mathrm{CO}, \mathrm{CH}$, and $\mathrm{CO}_{2}$ in the combustion products of alcohols were determined. Based on the obtained results we can conclude that the application of the proposed multi-point injection system operating on superheated alcohol fuels reduces both greenhouse gas emissions and harmful substances in exhaust gas emissions.
\end{abstract}

\section{Keywords}

alcohol engine, ICE, pure alcohol engine, engine ecological improvement
${ }^{1}$ Institute of Mechanics and Machine Building,

Volga State University of Technology

424000, 3 Lenin sq., Yoshkar-Ola, Republic of Mari El, Russian Federation

${ }^{*}$ Corresponding author, e-mail: konstantin.k-e@yandex.ru

\section{Introduction}

The current conception of the automotive industry development involves gradual replacement of fossil fuels by alternative ones, particularly alcohol-based fuels, which are renewable and more environmentally friendly. This can be achieved by improving the efficiency of mixture formation processes in internal combustion engines with positive ignition, which is a foreground task in the engine-building development worldwide.

Under promising technique to improve the quality of the external mixture formation can be subsumed the development of a system of superheated fuel injection. That system can be designed on the basis of either multi-point, central or direct fuel injections in ICEs with spark ignition. Nowadays multi-point fuel injection systems are by far dominant. The share of gasoline engines with it is today more than $80 \%$ [1]. Such systems with minor structural modifications can operate with both fossil and alternative fuels if appropriate fuel feed correction algorithms, which depend on the type of fuel, in electronic control units to apply.

It is currently known the internal combustion engines, which require gasoline of at least $15 \%$ in biofuel mixture for secure cold start [2-9]. The direct use of alcohol in fuel systems faces some technical problems especially at low temperature. For this purpose, gasoline is used to provide enough starting power for cars in cold weather.

The purpose of this work is to develop a system for multipoint injection of superheated alcohol fuels, which solves the problem of adapting the engine to run on absolute alternative fuels derived from renewable energy sources, with a minimum re-designing of fuel systems of existing internal combustion engines running on light fuels. It is assumed that the developed fuel injection system allows the engine to start and work securely on absolute (96\%) alcohol even in low temperature environments. 


\section{Materials and Method}

\subsection{Basic Principle Underlying the Proposed Injection System}

A distinctive feature of superheated fuel injection systems is explained with Fig. 1 and Fig. 2.

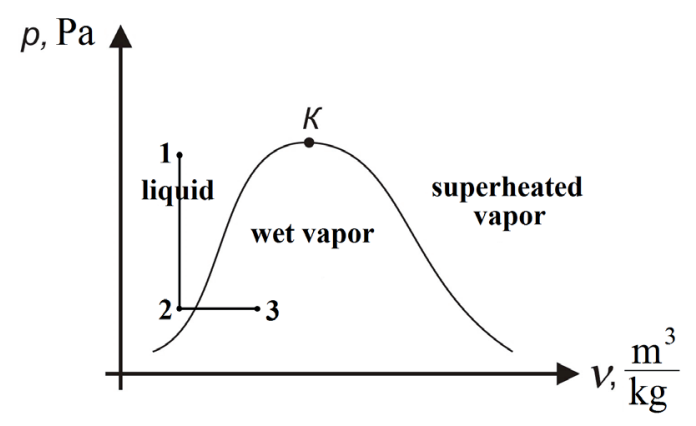

Fig. 1 A diagram of the ideal process of fuel parameters changes in the standard fuel injection system: $2-1$ is the process of increasing the fuel pressure with a pump, 1-2 is the process of dropping the fuel pressure when spraying through the injector, 2-3 is the process of heat supply from the inlet valve cap of a running engine to fuel, $K$ is the critical point

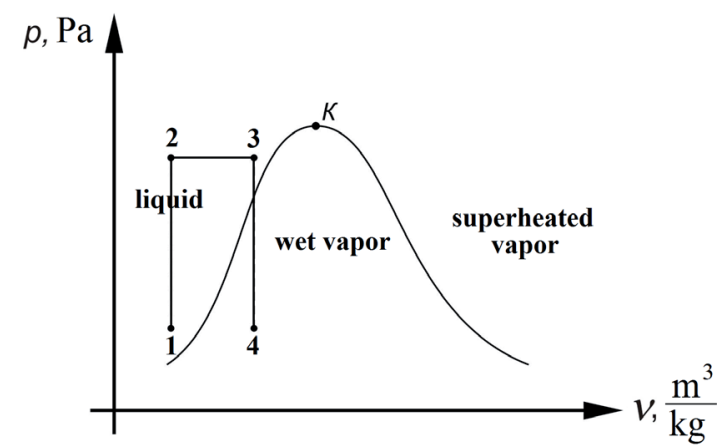

Fig. 2 A diagram of the ideal process of fuel parameters changes in the multipoint superheated fuel injection system: 1-2 is the process of increasing the fuel pressure with a pump, 2-3 is the process of heat supply to fuel in the system of the superheated fuel injection, 3-4 is the process of dropping the fuel pressure when spraying with the system of superheated fuel injection, $K$ is the critical point.

Let us assume that there is homogeneous fuel, for example, one of the lightest fractions of gasoline, pentane [10], and there is its diagram of interphase transition. As can be seen in Fig. 1, a standard multipoint injection system feeds fuel to the inlet valve cap in the liquid phase, while a superheated fuel injection system (Fig. 2) starts an injection in the liquid phase, and then the injector lets off the wet vapor. In the outlet of the injector fuel almost immediately begins to boil under the action of heat contained therein, and in the intake manifold wet vapor is formed, which then flows into the cylinders. Thereby by the end of the mixture formation process, ceteris paribus the intake manifold has more fuel in the vapor phase, which ultimately leads to better quality of both the mixture formation and the combustion processes in the engine cylinder, and an increase of heat utilization. So we can see that a superheated fuel injection system has a number of advantages in comparison to a conventional fuel injection system.

\subsection{A Multi-Point Superheated Fuel Injection System}

From technical, technological and economic points of view it is more rational to develop a superheated fuel injection system on the basis of the existing fuel systems. As an example, let us consider a diagram of a multipoint injection system operating on superheated alcohol fuels for a single-cylinder internal combustion engine (Fig. 3).

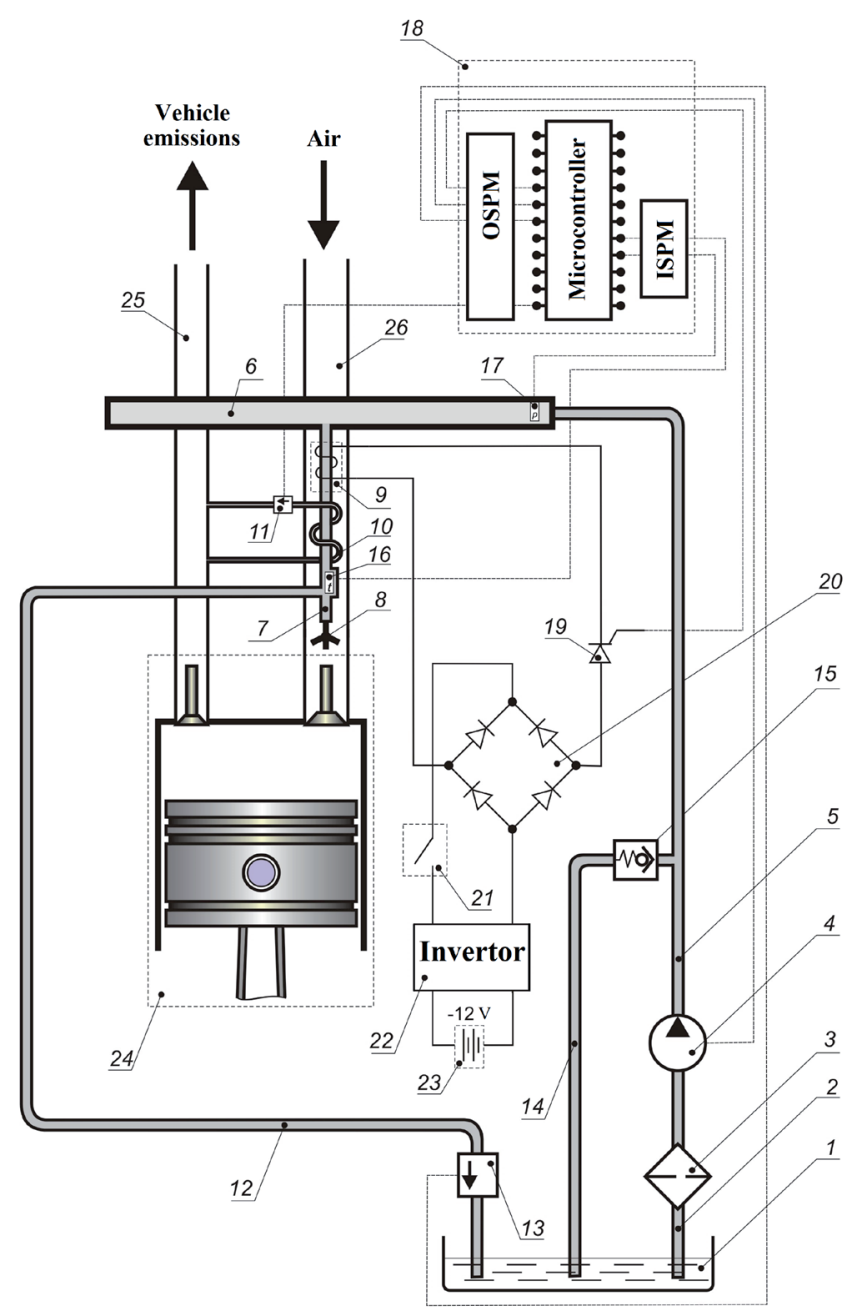

Fig. 3 A diagram of a superheated alcohol fuel injection system: 1 is a fuel tank; 2 is a fuel suction pipe; 3 is a fuel filter; 4 is a fuel pump; 5 is a fuel feed pipe of high pressure; 6 is a common rail; 7 is a superheating pipe; 8 is an injector; 9 is an electric heater; 10 is a gas heater; 11 is a controlled gas heater valve; 12 is a high pressure return piping; 13 is a controlled return valve; 14 is a low pressure return piping; 15 is an automatic return valve; 16 is a temperature sensor; 17 is a pressure sensor; 18 is an electronic control unit (ISPM is an input signal processing module; OSPM is an output signal processing module); 19 is a controlled thyristor; 20 is a diode rectifier bridge; 21 is an ignition key; 22 is an inverter; 23 is a battery; 24 is a piston-cylinderunit; 25 is an exhaust manifold; 26 is an intake manifold 
A regular electronic control system of internal combustion engines controls the engine running, the fuel injection time and the ignition point. To increase the amount of fuel injected, a program code of a regular system is changed.

The system works in the following way. After the ignition key is turned, the electric fuel pump 4 starts pumping the fuel into the fuel feed pipe of high pressure 5. If the pressure in the system reaches 4 atm., the automatic return valve 15 is actuated. Further, fuel goes to the common rail 6 equipped with a pressure sensor 17. From the common rail fuel enters the superheating pipe 7 where it is heated to a temperature close to the boiling point at the excess pressure by supplying heat from the electric heater 9 and/or from the gas heater 10. The temperature is controlled by the sensor 16 .

The electric heater heats the superheating pipe at the engine cold start. The heater is powered by $220 \mathrm{~V}$ obtained by converting DC voltage of the battery into AC voltage in the inverter output.

The gas heater 10 is a tube having an input and an output in the intake manifold 25 and a surface for heat exchange with the superheating pipe 7 .

The heaters 9 and 10 are controlled with the electronic control unit 18 by controlling the thyristor 19 and the valve 11 .

A fuel temperature at the outlet of the superheating pipe 7 is maintained at such level that fuel is on the boundary of interphase transition (point 3 in Fig. 2 should be located as close as possible to the boundary curve).

The need for the high-pressure return piping 12 and the individual channel for control the fuel pump energizing after the ignition turning off is dictated by the necessity of removing the superheated fuel from the superheating pipe 7. After stopping the engine, the electronic control unit outputs a control signal to the fuel pump 4 and the control valve 13, and overheated fuel passing through the high pressure return pipe 12 , which has a developed outer surface, cools down; and then it is expelled into the tank through the valve 13, where it mixes with colder fuel.

The described system for injection of superheated fuel provides the ability of internal combustion engines to start and work on pure alcohols.

\subsection{Method and Instruments Used}

In order to estimate the effective parameters of an ICE with a system for multi-point injection of superheated alcohol fuel (ethanol), its thermal design according to $[3,11]$ was made. As a baseline an 8-valve gasoline engine VAZ-2112 was selected, and its thermal design according to [11] was made as well. The calculations were made on the assumption that an air is supplied to the intake manifold of an engine under normal atmospheric conditions.

For experimental comparison of the effective parameters of a baseline ICE and a ICE with a superheated alcohol fuel injection system, eddy-current chassis dynamometer VT2/B1 (power measurement accuracy is $1 \%$, maximum power is $300 \mathrm{~kW}$ ) was used.

In order to evaluate toxicity of alcohol-based fuels combustion products in comparison with that of gasoline when using the developed multi-point superheated fuel injection system, in accordance with the diagram mentioned above (Fig. 3) a multipoint fuel injection system of the gasoline engine VAZ-2112 was modified.

Experiments were carried out using a certified calibrated gas analyzer INFAKAR-1000 and with the engine operating according to algorithms of "firmware" J5V05J16.

\section{Results and Discussion \\ 3.1 Thermal Efficiency and Heat Balance of Internal Combustion Engines}

Table 1 provides the calculated parameters of the baseline ICE (base) and the ICE with a superheated alcohol fuel injection system (project).

As seen in Table 1, the ICE working on superheated alcohol has the power reduced by approximately $20 \%$ compared with the baseline engine, and the specific fuel consumption increased more than twice. Based on the results in Table 1, the heat balance was made, and the obtained results are presented in Table 2.

According to figures presented in Table 2 the ICE working on superheated alcohol fuels has the efficiency of $19 \%$ less than that of the ICE working on gasoline due to lower temperature of alcohol combustion.

Table 1 Effective parameters of the engine VAZ-2112

\begin{tabular}{|c|c|c|c|c|c|c|c|c|c|c|c|}
\hline \multirow{2}{*}{ Type } & \multirow{2}{*}{ Parameter } & \multicolumn{10}{|c|}{$\mathrm{n}, \mathrm{rev} / \mathrm{min}$} \\
\hline & & 600 & 1,200 & 1,800 & 2,400 & 3,000 & 3,600 & 4,200 & 4,800 & 5,400 & 6,000 \\
\hline Project & $N_{e}, k W$ & 6.3 & 12.9 & 19.4 & 25.7 & 31.4 & 36.5 & 40.6 & 42.2 & 44.9 & 45.6 \\
\hline Base & $N_{e}, k W$ & 7.7 & 15.7 & 23.6 & 31.2 & 38.3 & 44.6 & 50 & 52.2 & 56.7 & 57.6 \\
\hline Project & $M_{e}, N^{*} m$ & 100.7 & 102 & 103 & 102 & 100 & 97 & 92 & 89 & 79 & 71 \\
\hline Base & $M_{e}, N^{*} m$ & 123 & 124 & 125 & 124 & 122 & 118 & 114 & 111 & 100 & 92 \\
\hline Project & $G_{f}, k g / h$ & 2.9 & 5.9 & 8.9 & 11.9 & 14.8 & 17.8 & 20.7 & 22.2 & 25.8 & 28.4 \\
\hline Base & $G_{f}, k g / h$ & 1.7 & 3.3 & 5.1 & 7.0 & 9.1 & 13 & 15.6 & 16.9 & 20.9 & 23.7 \\
\hline Project & $g_{f}, g / k W^{*} h$ & 462 & 457 & 458 & 463 & 473 & 488 & 509 & 522 & 575 & 623 \\
\hline Base & $g_{f}, g / k W^{*} h$ & 221 & 210 & 216 & 224 & 238 & 291 & 312 & 324 & 369 & 411 \\
\hline
\end{tabular}

Where, $N_{e}$ is the effective power; $M_{e}$ is the effective torque; $G_{f}$ is the hourly fuel consumption; $g_{f}$ is the specific fuel consumption. 
Table 2 Results of the engine VAZ-2112 heat balance

\begin{tabular}{|c|c|c|c|c|c|c|c|c|c|c|c|}
\hline \multirow{2}{*}{ Type } & \multirow{2}{*}{ Parameter } & \multicolumn{10}{|c|}{$\mathrm{n}, \mathrm{rev} / \mathrm{min}$} \\
\hline & & 600 & 1,200 & 1,800 & 2,400 & 3,000 & 3,600 & 4,200 & 4,800 & 5,400 & 6,000 \\
\hline Project & $q_{0}, \%$ & 100 & 100 & 100 & 100 & 100 & 100 & 100 & 100 & 100 & 100 \\
\hline Base & $q_{0}, \%$ & 100 & 100 & 100 & 100 & 100 & 100 & 100 & 100 & 100 & 100 \\
\hline Project & $q_{e}, \%$ & 28 & 29 & 29 & 28 & 28 & 27 & 26 & 25 & 23 & 21 \\
\hline Project & $q_{e x}, \%$ & 22 & 23 & 25 & 25 & 26 & 27 & 27 & 27 & 28 & 28 \\
\hline Base & $q_{e x}, \%$ & 25 & 26 & 27 & 28 & 29 & 29 & 30 & 30 & 30 & 30 \\
\hline Project & $q_{c m}, \%$ & 43 & 36 & 31 & 27 & 24 & 22 & 27 & 26 & 23 & 22 \\
\hline Base & $q_{c m}, \%$ & 38 & 36 & 35 & 33 & 31 & 29 & 27 & 26 & 23 & 22 \\
\hline Project & $q_{\text {rest }}, \%$ & 7 & 12 & 12 & 20 & 22 & 24 & 20 & 22 & 26 & 29 \\
\hline Base & $q_{\text {rest }}, \%$ & 3 & 3 & 4 & 5 & 7 & 10 & 12 & 14 & 19 & 22 \\
\hline
\end{tabular}

Where, $q_{0}$ is the percentage of the thermal power, which can be released in case of complete combustion of fuel injected into an engine (equals to $100 \%$ ); $q_{e}$ is the percentage of the thermal power equivalent to the effective work; $q_{e x}$ is the percentage of the thermal power lost with exhaust gases; $q_{c m}$ is the percentage of the thermal power imparted to the medium; $q_{\text {rest }}$ is the percentage of unaccounted losses of the thermal power.

Table 3 The power consumed by the heater

\begin{tabular}{lllllllllll}
\hline $\mathbf{n}, \mathbf{r e v} / \mathbf{m i n}$ & $\mathbf{6 0 0}$ & $\mathbf{1 , 2 0 0}$ & $\mathbf{1 , 8 0 0}$ & $\mathbf{2 , 4 0 0}$ & $\mathbf{3 , 0 0 0}$ & $\mathbf{3 , 6 0 0}$ & $\mathbf{4 , 2 0 0}$ & $\mathbf{4 , 8 0 0}$ & $\mathbf{5 , 4 0 0}$ & $\mathbf{6 , 0 0 0}$ \\
\hline$G_{\rho} \mathrm{kg} / \mathrm{h}$ & 2.9 & 5.9 & 8.9 & 11.9 & 14.8 & 17.8 & 20.7 & 22.2 & 25.8 & 28.4 \\
$N_{h}, k W$ & 0.235 & 0.478 & 0.720 & 0.963 & 1.198 & 1.441 & 1.675 & 1.797 & 2.088 & 2.300 \\
\hline
\end{tabular}

Where, $N_{h}$ is the power consumed by the gas heater 10 for heating the alcohol up to $120^{\circ} \mathrm{C}$.

A portion of heat taken away with exhaust gases can be used for the fuel heating with the gas heater 10 (Fig. 3).

Let us determine its amount. Knowing the maximum pressure of 4.4 atm., which is created in a conventional fuel injection system, we can determine a limiting temperature of the ethyl alcohol heating in the system, which is $120^{\circ} \mathrm{C}$.

Assuming that fuel is stored in the fuel tank at temperature of $0{ }^{\circ} \mathrm{C}$, we determine the power consumed by the heater in various speed ranges (see Table 3 ).

In steady-state thermal regime of the ICE working on superheated alcohol fuels, part of $q_{\text {rest }}$ will be used for the fuel heating, which leads to a reduction of both greenhouse gas emissions and environmental pollution associated with harmful substances in exhaust gases. The latter is achieved by reducing the amount of fuel consumed by the electricity generator to recharge the battery, energy of which is consumed for the alcohol superheating.

\subsection{Experimental Study}

\subsubsection{Measurements of the Effective Parameters of an ICE with a Superheated Alcohol Fuel Injection \\ System}

For experimental evaluation of the effective parameters, eddycurrent chassis dynamometer VT2 / B1 was used to determine the torque and the power of the baseline ICE and the ICE with a superheated alcohol fuel injection system.
As test engines we selected a baseline 8-valve gasoline engine VAZ-2112 and an 8-valve engine VAZ-2112, injection system of which had been modified according to the scheme of Fig. 3 .

The obtained results are presented in Table 4. When measuring the effective parameters, 10 measurements were carried out, blunders were eliminated, the average values were found, and random errors were determined.

As shown in Table 4, experimental results do not contradict theoretical ones, and the internal combustion engine operating on superheated alcohol has the power reduced by approximately $20 \%$ compared with the baseline engine, and the specific fuel consumption increased more than 1.5 times.

\subsubsection{Evaluation of Toxicity of Combustion Products of ICE Operating on Superheated Alcohol}

The results of measurements of the level of combustion products toxicity of gasoline are shown in Fig. 4.

Measurements were made at various values of the air ratio in the range from 0.8 to 1.5 .

The results of measurements of the level of combustion products toxicity of $96 \%$ hydrous ethanol solution are shown in Fig. 5. Measurements were made at various values of the air ratio in the range from 0.8 to 1.5 .

It should be noted an inverse dependence of content of $\mathrm{CH}$ in the combustion products and a complex dependence of content of $\mathrm{CO}_{2}$. From the standpoint of achieving the minimum 
Table 4 Experimental evaluation of the effective parameters of a baseline ICE and an ICE with a modified injection system

\begin{tabular}{|c|c|c|c|c|c|c|c|c|c|c|c|}
\hline Type & $\mathrm{n}, \mathrm{rev} / \mathrm{min}$ & 600 & 1,200 & 1,800 & 2,400 & 3,000 & 3,600 & 4,200 & 4,800 & 5,400 & 6,000 \\
\hline Modified & $N_{e}, k W$ & 6.2 & 12.6 & 19.2 & 24.9 & 30.5 & 36.2 & 39.6 & 43.2 & 42.4 & 43.3 \\
\hline Baseline & $N_{e}, k W$ & 7.5 & 15.2 & 23.0 & 30.1 & 37.1 & 43.3 & 48.8 & 54.3 & 56.5 & 55.9 \\
\hline Modified & $M_{e}, N^{*} m$ & 99 & 100 & 102 & 99 & 97 & 96 & 90 & 86 & 75 & 69 \\
\hline Baseline & $M_{e}, N^{*} m$ & 119 & 121 & 122 & 120 & 118 & 115 & 111 & 108 & 100 & 89 \\
\hline Modified & $G_{\rho} \mathrm{kg} / \mathrm{h}$ & 2.5 & 5.4 & 8.8 & 11.2 & 14.5 & 17.2 & 20.2 & 21.5 & 24.7 & 27.9 \\
\hline Baseline & $G_{f}, k g / h$ & 1.8 & 3.2 & 5.0 & 7.2 & 9.5 & 12.9 & 15.7 & 16.9 & 21.2 & 24.1 \\
\hline Modified & $g_{f} g / k W^{*} h$ & 402.1 & 429.9 & 457.9 & 450.4 & 476.1 & 475.5 & 497.6 & 510.6 & 582.7 & 643.9 \\
\hline Baseline & $g_{f} g / k W^{*} h$ & 240.9 & 210.6 & 217.5 & 238.9 & 256.4 & 297.7 & 311.5 & 321.8 & 375.1 & 431.2 \\
\hline
\end{tabular}

Where, $N_{e}$ is the effective power; $M_{e}$ is the effective torque; $G_{f}$ is the hourly fuel consumption; $g_{f}$ is the specific fuel consumption.

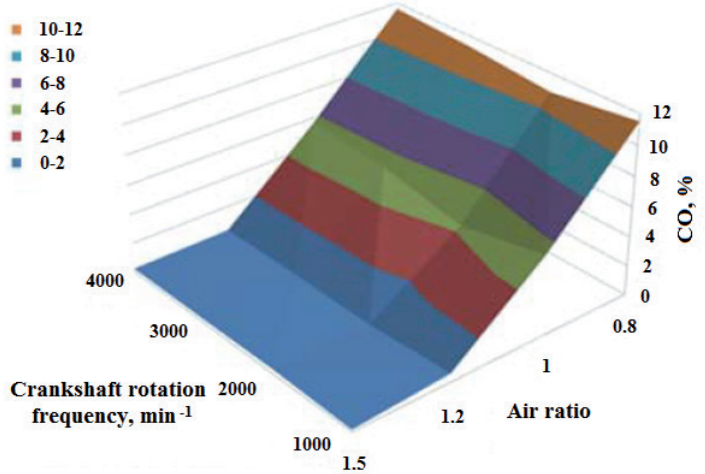

(a)

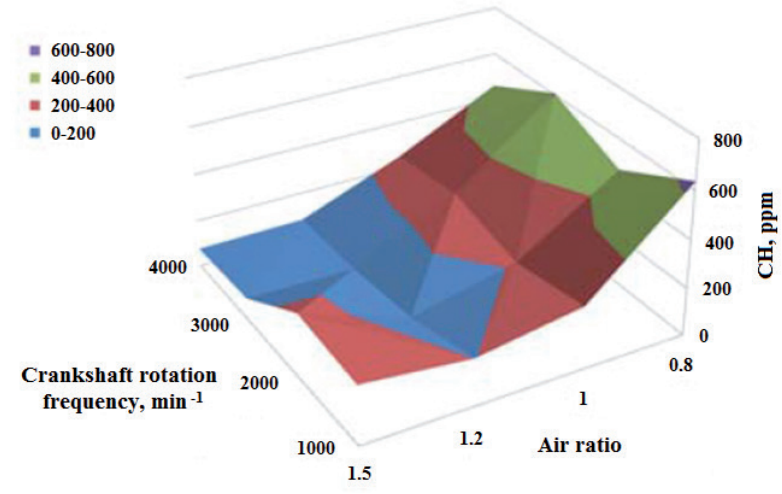

(b)

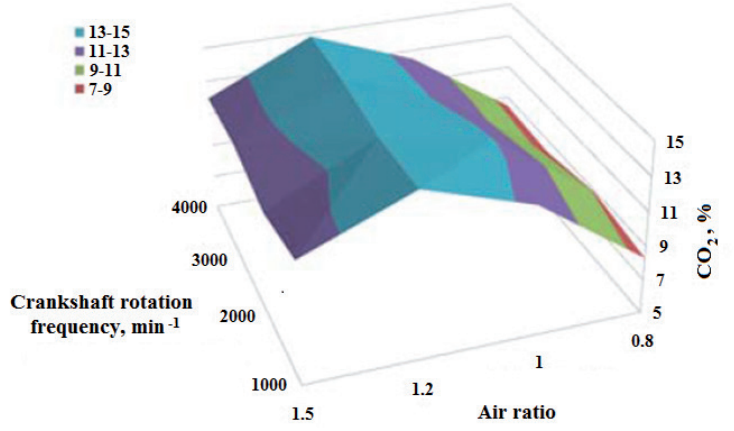

(c)

Fig. 4 The contents of (a) $\mathrm{CO}$; (b) $\mathrm{CH}$; and (c) $\mathrm{CO}_{2}$ in the gasoline combustion products.

level of toxic components in combustion products it is advisable to keep the engine working at low and medium speeds and at lean mixture at the air ratio close to 1.5 as well. A higher content level of $\mathrm{CH}$ is due to the presence of water in the fuel composition and also the worse conditions for ethanol combustion on the periphery of the combustion chamber. In all regimes of engine working on hydrous ethanol, total emissions of carbon dioxide are less than when using gasoline. Reduction of emissions is down to $50 \%$.

Measurements of the toxicity level of the combustion products of isopropyl alcohol were carried out at various values of the air ratio ranging from 0.83 to 1.46 . The results are shown in Fig. 6.

As is the case with ethanol, the lowest level of total emissions of pollutants is observed in the case of lean mixture engine operations $(\alpha=1.46)$. In all regimes of engine working on isopropyl alcohol total carbon dioxide emissions almost equal and sometimes even exceed that level when working on gasoline.

Measurements of the level of toxicity of the combustion products of n-butyl alcohol were carried out at various values of the air ratio in the range from 0.7 to 1.5. The results are shown in Fig. 7.

The minimum level of toxic components of the combustion products of n-butanol is observed at the air ratio of 1.18 , which is not corresponding with the trends for ethanol and isopropanol. Furthermore, attention was drawn to the fact that the dependence of the contents of unburned hydrocarbons in the products of combustion on the air ratio is inverse in comparison with that of isopropyl and ethyl alcohols. 


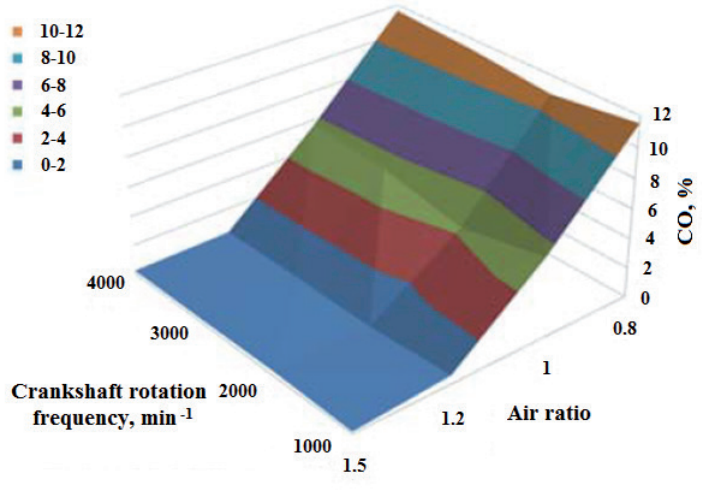

(a)

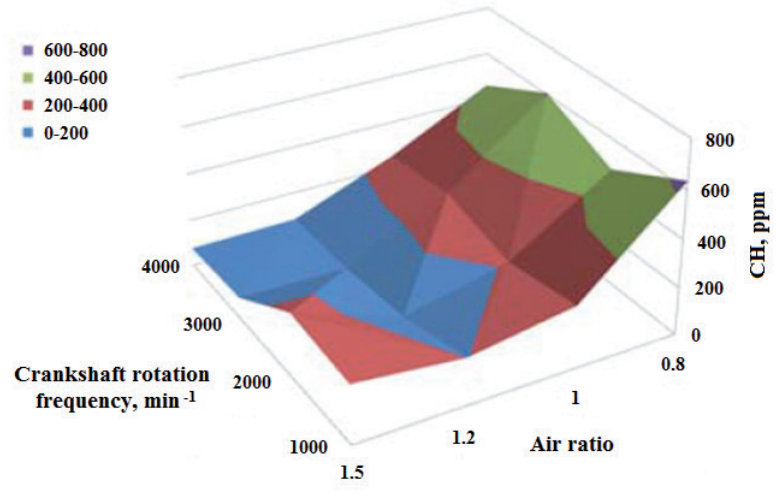

(b)

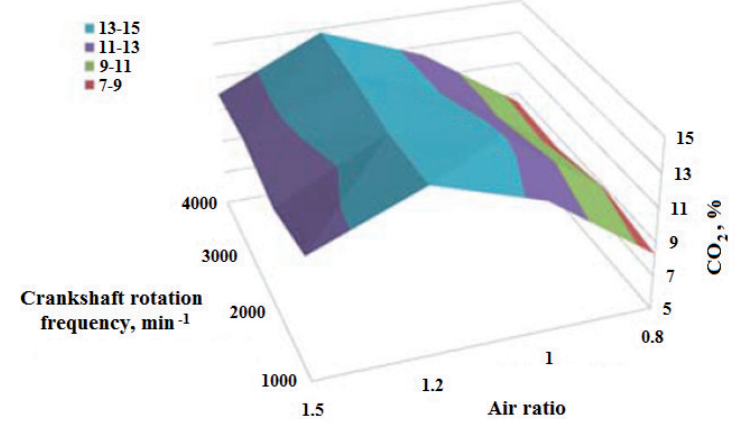

(c)

Fig. 5 The contents of (a) $\mathrm{CO}$; (b) $\mathrm{CH}$; and (c) $\mathrm{CO}_{2}$ in the ethanol combustion products.

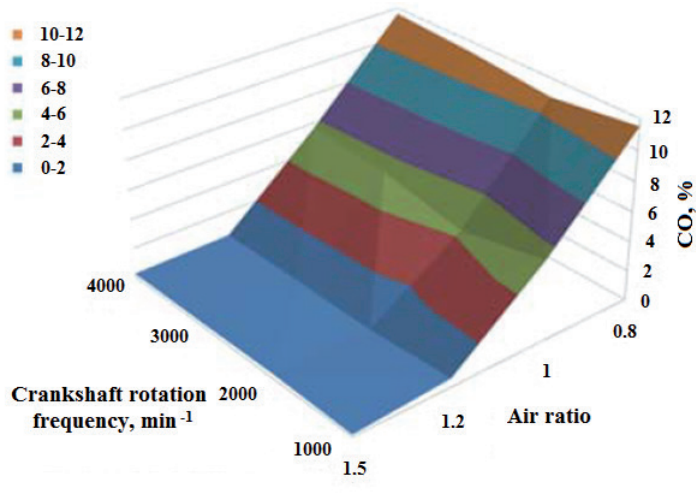

(a)

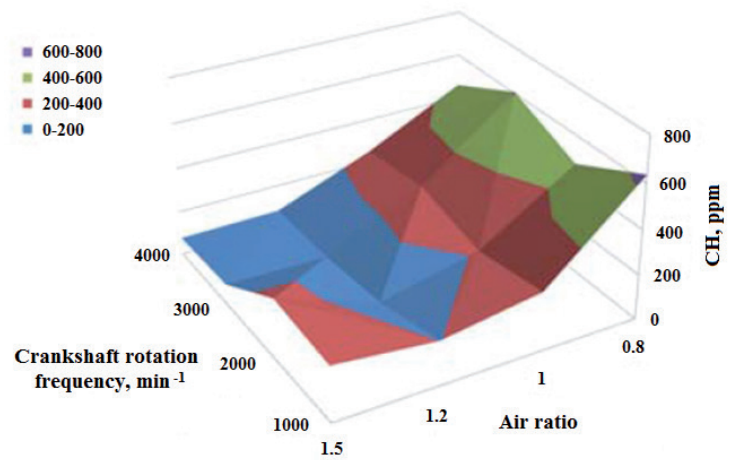

(b)

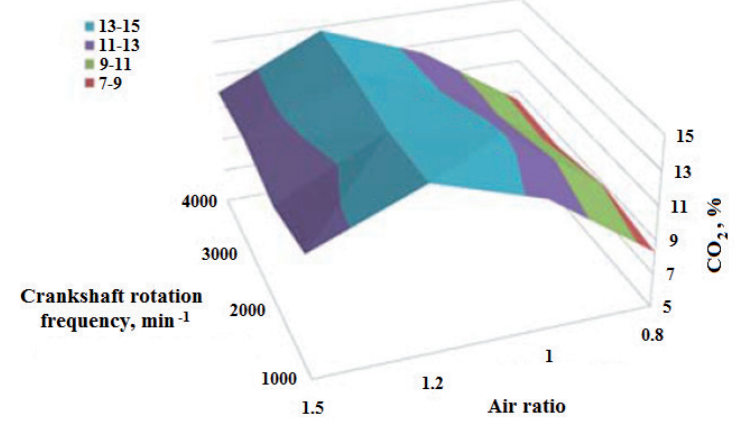

(c)

Fig. 6 The contents of (a) $\mathrm{CO}$; (b) $\mathrm{CH}$; and (c) $\mathrm{CO}_{2}$ in the isopropanol combustion products. 


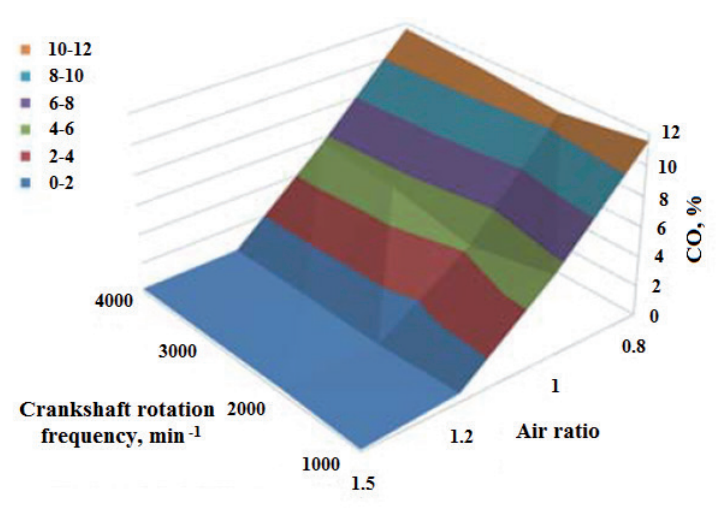

(a)

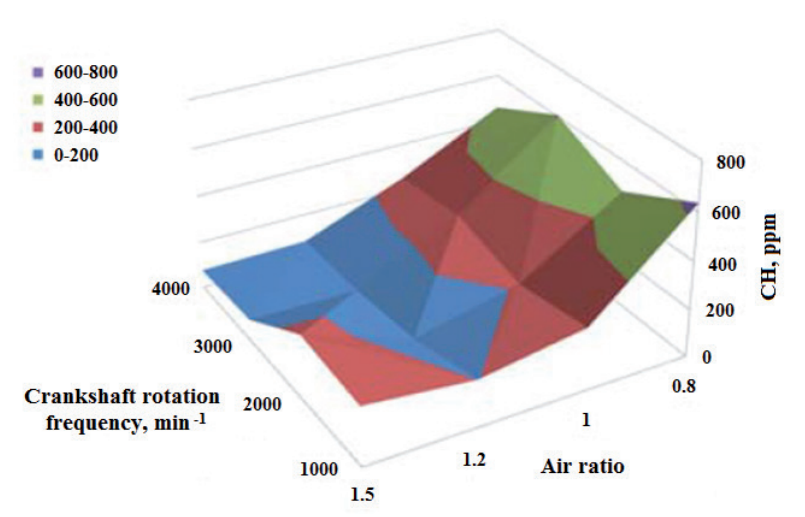

(b)

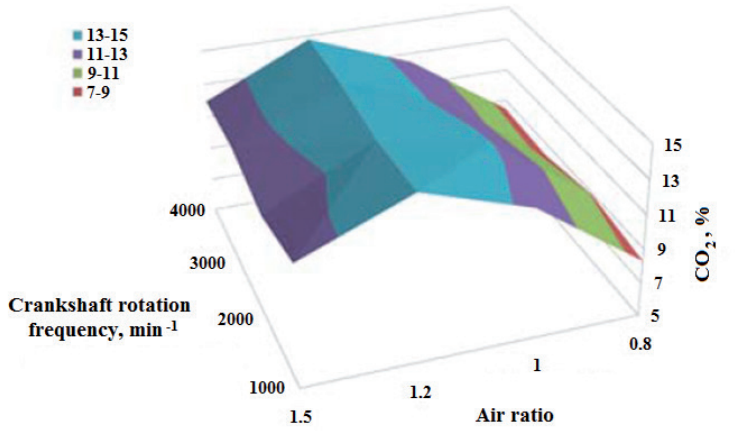

(c)

Fig. 7 The contents of (a) $\mathrm{CO}$; (b) $\mathrm{CH}$; and (c) $\mathrm{CO}_{2}$ in the n-butanol combustion products.

\section{Conclusions}

Based on the obtained results, not taking into account the power reduction of an internal combustion engine when using superheated alcohol fuels, it can be noted that the use of a superheated alcohol fuel injection system allows the following:

1. to increase the quality of the mixture formation of a gasoline engine by feeding fuel into the intake system in a state of wet vapor;

2. to solve the advanced task of adapting the engine to run on absolute alcohol derived from renewable energy sources with slight modifications of traditional internal combustion engines running on light fuels;

3. to start an engine with positive ignition operating on dehydrated and non-dehydrated alcohols in a wide temperature range (using a superheated fuel injection system allows the cold starting on alcohols at a temperature below $0{ }^{\circ} \mathrm{C}$; the use of the starting preheaters of coolant allows sinking a temperature of cold start to minus $30^{\circ} \mathrm{C}$ );

4. to improve the environmental safety of internal combustion engines (portion of exhaust heat is utilized for preheating fuel to desired temperature; from a point of view of minimizing emissions of carbon dioxide, it is most preferably using $96 \%$ hydrous ethanol (reduction of carbon dioxide emissions compared with gasoline ones can reach $45 \%$ at the air ratio close to 1.5 , and at the engine speed of $1,000 \mathrm{rev} / \mathrm{min})$ ).
Our future work will be aimed at improving the efficiency of an internal combustion engine with a multi-point superheated alcohol fuel injection system, which can be achieved by the following: 1) the increase of the compression ratio (i.e. the reduction of combustion volume), since alcohol has the heightened antiknock value; 2) the use of heat energy of motor oil, coolant and combustion products for the fuel superheating; 3 ) modifying the control algorithms of an electric generator operation.

Also we plan to apply the proposed technique of fuel superheating to direct fuel injection systems of internal combustion engines with spark ignition.

\section{References}

[1] Dragomirov, S. G. "Intensifikatsiya vneshnego smeseobrazovaniya v avtomobilnykh dvigatelyakh s vpryskom benzina." (Intensification of the External Mixture Formation in Engines with Gasoline Injection.) Unpublished Doctoral dissertation,Vladimir State University, Vladimir, Russia, 2002. (in Russian)

[2] Irimescu, A. "Study of cold start air-fuel mixture parameters for spark ignition engines fueled with gasoline-isobutanol Blends." International Communications in Heat and Mass Transfer. 37(9), pp. 1203-1207. 2010. DOI: 10.1016/j.icheatmasstransfer.2010.07.009

[3] Kolchin, A. I. "Rastchet avtomobilnykh i traktornykh dvigateley." (Design of Automobile and Tractor Engines.) Vysshaya shkola, Moscow, 2003. (in Russian). 
[4] Mofijur, M., Rasul, M. G., Hyde, J. "Recent Developments on Internal Combustion Engine Performance and Emissions Fuelled With BiodieselDiesel-Ethanol Blends." Procedia Engineering. 105, pp. 658-664. 2015. DOI: $10.1016 /$ j.proeng.2015.05.045

[5] Myagkov, L. L., Mahkamov, K., Chainov, N. D., Makhkamova, I. "11 Advanced and Conventional Internal Combustion Engine Materials." In: Alternative Fuels and Advanced Vehicle Technologies for Improved Environmental Performance. Towards Zero Carbon Transportation (Folkson, R., ed.), pp. 370-392. Woodhead Publishing, UK. 2014. DOI: $10.1533 / 9780857097422.2 .370$

[6] Pearson, R. J., Turner, J. W. G. "Improving the Use of Liquid Biofuels in Internal Combustion Engines." In: Advances in Biorefineries, Biomass and Waste Supply Chain Exploration. (Waldron, K. W., ed.), pp. 389-440. Woodhead Publishing, UK. 2014. DOI: 10.1533/9780857097385.2.389

[7] Shahir, S. A., Masjuki, H. H., Kalam, M. A., Imran, A., Ashraful, A. M. "Performance and Emission Assessment of Diesel-Biodiesel-Ethanol/ Bioethanol Blends as a Fuel in Diesel Engines: A Review." Renewable and Sustainable Energy Reviews. 48, pp. 62-78. 2014.

DOI: 10.1016/j.rser.2015.03.049
[8] Tutak, W., Lukács, K., Szwaja, S., Bereczky, A. "Alcohol-diesel fuel combustion in the compression ignition engine." Fuel. 154, pp. 196-206. 2015. DOI: $10.1016 /$ j.fuel.2015.03.071

[9] Yilmaz, N., Vigil, F. M. "Potential use of a blend of diesel, biodiesel, alcohols and vegetable oil in compression ignition engines." Fuel. 124, pp. 168-172. 2014. DOI: 10.1016/j.fuel.2014.01.075

[10] Khovaka, M. S. "Avtomobilnyedvigateli." (Automobile Engines.) Mashinostroeniye, Moscow, 1977. (in Russian).

[11] Vyrubov, D. N., Ivashenko, N. A., Ivin, V. I. "Dvigateli vnutrennego sgoraniya: Teoriya porshnevykhi kombinirovannykh dvigateley." (Internal Combustion Engines: the Theory of Piston and Combined Engines.) Mashinostroeniye, Moscow. 1983, (in Russian) 